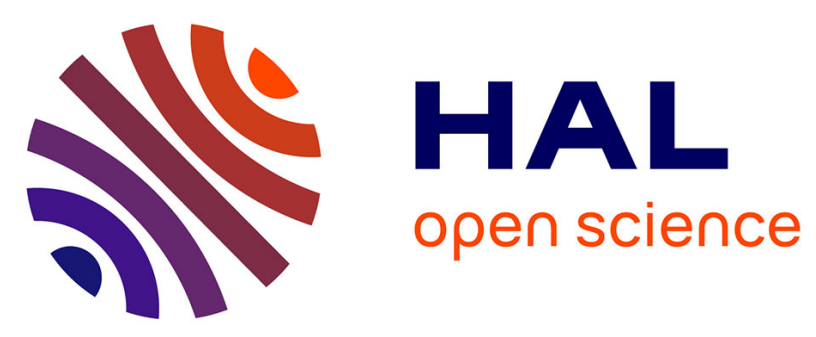

\title{
Coupled Modeling of Sedimentary Basin and Geomechanics: A Modified Drucker-Prager Cap Model to Describe Rock Compaction in Tectonic Context
}

\author{
N. Guy, D. Colombo, J. Frey, T. Cornu, Marie-Christine Cacas-Stentz
}

\section{- To cite this version:}

N. Guy, D. Colombo, J. Frey, T. Cornu, Marie-Christine Cacas-Stentz. Coupled Modeling of Sedimentary Basin and Geomechanics: A Modified Drucker-Prager Cap Model to Describe Rock Compaction in Tectonic Context. Rock Mechanics and Rock Engineering, 2019, 52 (10), pp.3627-3643. 10.1007/s00603-019-01783-y . hal-02413220

\section{HAL Id: hal-02413220 \\ https: / hal-ifp.archives-ouvertes.fr/hal-02413220}

Submitted on 16 Dec 2019

HAL is a multi-disciplinary open access archive for the deposit and dissemination of scientific research documents, whether they are published or not. The documents may come from teaching and research institutions in France or abroad, or from public or private research centers.
L'archive ouverte pluridisciplinaire HAL, est destinée au dépôt et à la diffusion de documents scientifiques de niveau recherche, publiés ou non, émanant des établissements d'enseignement et de recherche français ou étrangers, des laboratoires publics ou privés. 


\title{
Coupled modelling of sedimentary basin and geomechanics: A modified Drucker-Prager Cap model to describe rock compaction in tectonic context
}

\author{
N. Guy · D. Colombo - J. Frey • T. \\ Cornu • M.C Cacas-Stentz
}

Received: date / Accepted: date

\begin{abstract}
The aim of basin modeling is to characterise fluids and rocks in a basin considering its history and data partly describing its present state. In usual basin simulators, only a simplified description of geomechanics based on the hypothesis of oedometric strain is used. In order to both enhance the modelling of basin history and to characterise actual in situ stresses, the effect of stress redistribution, horizontal stresses and strain variations during basin history should be considered. To address this point, a coupled basingeomechanics framework based on a new constitutive law is proposed in this paper using the prototype simulator $\mathrm{A}^{2}$. This framework has been built to provide relevant results for various kinds of basin cases including tectonic loading. A finite strain poro-mechanical approach is considered along with an modified Drucker-Prager Cap model to describe rock compaction under natural sedimentation, erosion and tectonics. The constitutive model can be seen as a tensorial extension of the compaction models of Athy or Schneider as it allows to recover the same behaviour in oedometric context. Simple test cases are modelled considering typical sand or shale properties, emphasing the effect of tectonic loading on present day pore pressures and in situ stresses. It appears that even relatively moderate tectonic loading ( $5 \%$ of horizontal strain) can lead to overpressures of several hundreds of bars and to a complete change in in situ stress regime for deeply buried layers (above a depth of 2000 meters).

N. Guy

IFP Energies nouvelles, 1 \& 4 avenue Bois-Préau, 92852 Rueil-Malmaison Cedex, France

Tel.: +33-1-47527018

Fax: $+33-1-42576000$

E-mail: nicolas.guy@ifpen.fr

D. Colombo, J. Frey, M.C. Cacas Stentz

IFP Energies nouvelles, 1 \& 4 avenue Bois-Préau, 92852 Rueil-Malmaison Cedex, France

T. Cornu

Total Exploration Production Research and Development, avenue Larribeau, 64000 Pau, France
\end{abstract}


Keywords Basin modelling · Compaction · Geomechanical coupling · Finite strain 


\section{List of symbols}

$\sigma_{\text {eff }} \quad$ Basin modelling vertical effective stress

$\sigma_{v} \quad$ Vertical total stress

$p \quad$ Pore pressure

$\phi \quad$ Eulerian porosity

$\phi_{0} \quad$ Initial porosity

$\kappa \quad$ Athy's law compaction parameter

$\phi_{r} \quad$ Residual porosity

$\phi_{a} \quad$ Schneider's law compaction parameter

$\phi_{b} \quad$ Schneider's law compaction parameter

$\sigma_{a} \quad$ Schneider's law compaction parameter

$\sigma_{b} \quad$ Schneider's law compaction parameter

$\boldsymbol{\sigma} \quad$ Total stress tensor

$\rho_{h} \quad$ Homogeneized density

$\boldsymbol{g} \quad$ Gravity

$\rho_{f} \quad$ Fluid density

$\rho_{s} \quad$ Solid density

$t \quad$ Time

$\Phi \quad$ Lagrangian porosity

$J \quad$ Jacobian of the geometrical transformation

$\boldsymbol{\eta} \quad$ The fluid flow

$\boldsymbol{k} \quad$ The permeability tensor

$\boldsymbol{\nabla} \quad$ Gradient operator

$\Omega_{0} \quad$ Initial state

$\Omega_{t} \quad$ Current state

$\Omega_{u} \quad$ Unloaded state

$\boldsymbol{F}^{\boldsymbol{t}} \quad$ Transformation between the states $\Omega_{0}$ and $\Omega_{t}$

$\boldsymbol{F}^{\boldsymbol{p}} \quad$ Transformation between the states $\Omega_{0}$ and $\Omega_{u}$

$\boldsymbol{F}^{e} \quad$ Transformation between the states $\Omega_{u}$ and $\Omega_{t}$

$\phi_{p} \quad$ Plastic eulerian porosity

$\phi_{u} \quad$ Eulerian porosity of the unloaded state

$J^{p} \quad$ Determinant of the transformation $\boldsymbol{F}^{p}$

$\sigma^{\prime} \quad$ Effective stress tensor

$\sigma_{z z}^{\prime} \quad$ Vertical effective stress

$b \quad$ Biot coefficient

$M \quad$ Biot modulus

$\Omega \quad$ Spin rate tensor

$\boldsymbol{d}_{\boldsymbol{p}} \quad$ plastic strain rate tensor

$\boldsymbol{d} \quad$ total strain rate tensor

$F_{s} \quad$ Yield surface associated with shear plasticity

$G_{s} \quad$ Plastic potential associated with shear plasticity

$F_{c} \quad$ Yield surface associated with plastic compaction

$G_{c} \quad$ Plastic potential associated with plastic compaction

$q \quad$ Equivalent stress 


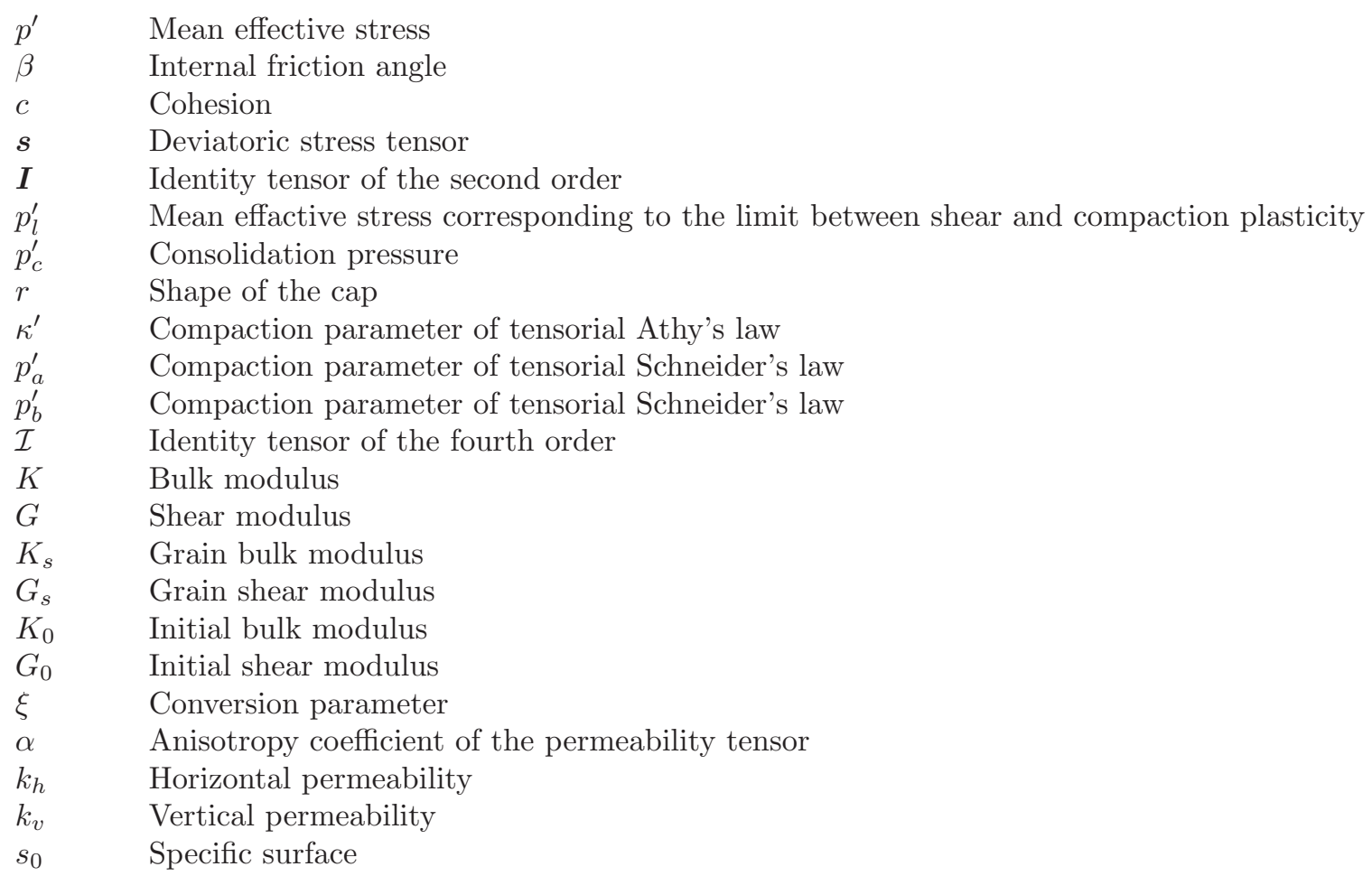




\section{Introduction}

Sedimentary basin modelling aims at providing a relevant description of basin history at geological time scale (Hantschel and Kauerauf, 2009; Schneider et al., 1996). Basin numerical simulation is used to predict pore pressures, thermicity, fluid nature and petrophysical properties such as porosity and permeability. A basin simulator describes fluid flow in an underground which is subjected to changes in geometry and rock transfer properties such as porosity and permeability. A key issue in basin modeling is the prediction of the evolution of these transfer properties.

A basin simulator should be able to provide the scenario of basin evolution from the surface to the metamorphic zone at its base, which can be located at more than $7000 \mathrm{~m}$ deep. As rocks are buried deeper and deeper because of sedimentation, they can be subjected to various physical phenomena modifying their hydraulic properties. The evolution of fluid transfer properties of buried rocks is determined by various and complex physical phenomena (Hedberg, 1936; Doyen, 1988; Yang and Aplin, 2010). The evolution of rock porosity and permeability is mainly governed by overpressure, mechanical compaction, chemical compaction and natural fracturing. Rock compaction induces a porosity decrease and therefore a permeability decrease in general which are commonly described in basin modeling considering permeabilityporosity relationships (Doyen, 1988; Yang and Aplin, 2010). Rock burial is usually considered as the dominating factor controlling porosity changes. Indeed, according to Hedberg (1936) for instance, the mechanical compaction associated with stress state and tectonics has to be considered as the main phenomenon to model the porosity decrease of silico-clastic materials at least in upper layers. Nevertheless, for deeper layers (at least 3000 to 4000 meters deep), the dominating phenomenon can be chemical compaction for numerous kind of sandstones as shown in figure 1. The chemical compaction can even be the dominating compacting phenomenon at lower depths (of about hundreds of meters) for carbonates. Chemical compaction also lead to changes in porosity. The main mechanism is pressure dissolution which is linked to precipitation and diffusion phenomena. Chemical compaction is governed by temperature (Houseknecht, 1984), grain size (Houseknecht, 1988), pore pressure and, water salinity and $\mathrm{pH}$. These phenomena can be modelled with a visco-plastic behaviour as it has been shown in an oedometric context (Schneider et al., 1996) or considering a proper tensorial description of in situ stresses (Brüch et al., 2018). Another phenomenon that could be considered at the considered time scales is creep, nevertheless it is usually ignored in basin modelling for the sake of simplicity. In the present paper, we will focus on mechanical compaction and evaluate rock behaviour in the upper layers (down to about 4000 meters deep) and we do not consider the case of early and significant chemical compaction.

Natural fracturing is also a key issue in basin history as it has a significant influence on transfer properties. Natural fracturing can be caused by various phenomena such as tectonic loadings, poroelastic properties of rock, overpres- 
sures, high sedimentation rates or coupled geomechanical effects (Secor, 1969; Luo and Vasseur, 2002; Sibson, 2003; Ouraga et al., 2017, 2018). All these phenomena are related to the in situ stress state, including non-vertical stresses.

Mechanical compaction is related to effective stress (Coussy, 1991). The effective stress is the stress that effectively load the solid part of the porous media. A change in effective stress can lead to a porosity decrease through grain sliding as an example (Giles, 1997). The effective stress depends on pore pressure and total stress. In the underground, total stresses are mainly due to gravity and tends to increase with burial and sedimentation. Nevertheless other mechanisms such as tectonics, stress redistribution and associated change in non-vertical stresses can have an influence on rock compaction (Luo et al., 1998; Obradors-Prats et al., 2017) and pore pressure.

A purely vertical modeling of geomechanics is commonly embedded in basin simulator to describe rock compaction (Schneider et al., 1996; Schneider and Hay, 2001). Indeed, in this framework, a scalar stress depending on the weight of surrounding rocks and fluids is computed. This stress is used to define effective stress and to model compaction using empirical laws such as Athy and Schneider compaction models. The time dependent behaviour of rock has been studied and underlined at various time scales and in various contexts (Wasantha et al., 2015; Sulem et al., 1987; Debernardi and Barla, 2009; Ma, 2017). Nevertheless these aspects of the rock behaviour are difficult to characterise at the geological time scale. Basin compaction models are based on the simplifying hypothesis that time depending aspects of the rock behaviour can be neglected, excepted the ones eventually related to chemical interactions. This approach hase been widely used to model basin history and it has allowed to reproduce present-day porosity and pore pressure in various contexts (Hantschel and Kauerauf, 2009; Athy, 1930; Smith, 1971; Schneider et al., 1996; Schneider and Hay, 2001), usually when tectonic loadings are not key issues. The use of a scalar stress and of a scalar effective stress does not account for the effect of in situ stress redistribution, horizontal stress variability and tectonic loading. Numerous basins are submitted to tectonic loading that lead to horizontal stress changes, overpressures, horizontal strains and that commonly lead to basin faulting. In these basins, the oedometric hypothesis is not relevant. These limitations are well known and furthermore, modelling geomechanics considering horizontal stresses could lead to a characterisation of present day in situ stresses that conventional basin model cannot provide. Many models have been built to overcome them considering the fact that rock compaction commonly leads to finite strain in the context of basin modelling. As an example, Bourgeois (Bourgeois, 1997) has modified the formulation to make it relevant in the framework of one dimension finite strains. Also, Bernaud et al. (Bernaud et al., 2002, 2006) have proposed a tridimensionnal approach to describe the modification of the micro-structure of rock through micro-mechanics.

More recent works have been focusing on the study of advanced geomechanical models applied to synthetic test cases (Guilmin, 2012; Maghous et al., 2013; Obradors-Prats et al., 2017; Brüch et al., 2018). Nevertheless, these models are not related to usual basin modelling compaction laws that are linking 
vertical effective stress to porosity (Hantschel and Kauerauf, 2009; Athy, 1930; Smith, 1971; Schneider et al., 1996; Schneider and Hay, 2001) considering empirical approaches. In the present paper a constituve law based on a coupled basin-geomechanics framework is provided. This constitutive law is written to be the most simple tensorial extension of the usual scalar basin compaction models. The coupled framework has been built considering poro-mechanics, finite strain and a modified Drucker-Prager Cap model to describe rock compaction. In the first part of the paper the new constitutive law is presented along with the theoritical framework of the prototype simulator $\mathrm{A}^{2}$. The constitutive law is built to reproduce respectively Athy and Schneider compaction models in oedometric conditions. In the second part of the paper the model is used to describe the effect of tectonic compaction on in situ stress, porosity and pore pressure. In order to do so, the sedimention of several columns of rock is modeled considering various tectonic scenarios and rock behaviour.

\section{Modelling approach}

Conventional basin simulators are based on a purely vertical modeling of geomechanics. Terzaghi hypothesis (Terzaghi, 1923) and sign convention of continuum mechanics (compressive stresses are negative) leads to the following relation

$$
\sigma_{e f f}=\sigma_{v}+p
$$

with $\sigma_{\text {eff }}$ a vertical effective stress defined for basin modelling, $\sigma_{v}$ a vertical stress deduced from the weight of surrounding layers and $p$ pore pressure. The effective stress is related to porosity to model compaction by means of various laws. Two of the most common are the model of Athy (Athy, 1930) and the model of Schneider (Schneider et al., 1996). Athy's model was initially linking porosity with depth and it has been written in terms of effective stress later (Smith, 1971) leading to the relation

$$
\phi=\phi_{0} e^{\kappa \sigma_{e f f}}
$$

with $\phi$ the eulerian porosity, $\phi_{0}$ the initial porosity and $\kappa$ a compaction parameter.

Schneider's model is based on five parameters and on two exponential terms to model both a close to surface behaviour (for low effective stresses, for layers buried at less than 500-1000 meters) and compaction at larger depth. This model reads

$$
\phi=\phi_{r}+\phi_{a} e^{\sigma_{e f f} / \sigma_{a}}+\phi_{b} e^{\sigma_{e f f} / \sigma_{b}}
$$

where $\phi_{r}$ is the residual porosity and where $\phi_{a}, \phi_{b}, \sigma_{a}$ and $\sigma_{b}$ are compaction parameters.

These empirical formulations have been built neglecting the effect of horizontal strains on porosity change. They can provide relevant compaction modelling in oedometric context. They have been and are still widely used in practical cases (Woillez et al., 2017; Faille et al., 2014; Hantschel and Kauerauf, 
2009). In order to be able to model properly the effect of horizontal stress and strain on porosity changes, a constitutive law presented here provides results as relevant as Athy and Schneider models in oedometric context and can also take into account the effect of horizontal stress and strain in basin history. The law is based on the theoretical framework of poro-mechanics in finite strain that has already been considered in an isothermal (Maghous et al., 2013) or thermal context (Brüch et al., 2018).

\subsection{Theoretical framework}

The conservation equations considered here are stress equilibrium and mass conservation. For the sake of simplicity we assume an iso-thermal context and a saturated and isotropic porous media. The sign convention of continuum mechanics (compressive stresses are negative) is adopted here. The stress equilibrium reads

$$
\operatorname{div} \boldsymbol{\sigma}+\rho_{h} \boldsymbol{g}=\mathbf{0}
$$

with $\boldsymbol{\sigma}$ the total stress tensor, $\boldsymbol{g}$ the gravity and $\rho_{h}$ the homogeneized density that reads

$$
\rho_{h}=\phi \rho_{f}+(1-\phi) \rho_{s}
$$

where $\rho_{f}$ and $\rho_{s}$ are fluid and solid density. The mass conservation can be expressed as

$$
\frac{d}{d t}\left(\rho_{f} \Phi\right)=J \operatorname{div}\left(\rho_{f} \boldsymbol{\eta}\right)
$$

with $\Phi$ the lagrangian porosity, $J$ the Jacobian of the geometrical transformation $\boldsymbol{F}^{t}$ defined later and is equal to the ratio of the volume of a porous elementary between its initial and current state, $\boldsymbol{\eta}$ the fluid flow and $t$ the time. The law of Darcy reads

$$
\boldsymbol{\eta}=\boldsymbol{k}\left(\rho_{f} \boldsymbol{g}-\nabla p\right)
$$

where $\boldsymbol{k}$ is the permeability tensor.

In order to characterise the state of the porous medium, we consider a transformation $\boldsymbol{F}^{\boldsymbol{t}}$, linked with a mechanical loading and a change in pore pressure describing a change from the state $d \Omega_{0}$ to $d \Omega_{t}$. We also consider the state $d \Omega_{u}$ that results from the unloading of the state $d \Omega_{t}$. The state $d \Omega_{u}$ is obtained with a zero stress and pore pressure. Therefore, as shown in figure 2, we can define the plastic transformation $\boldsymbol{F}^{p}$ as a transformation changing $d \Omega_{0}$ in $d \Omega_{u}$ and the elastic transformation $\boldsymbol{F}^{e}$ changing $d \Omega_{u}$ in $d \Omega_{t}$. From this framework we introduce a plastic eulerian porosity characterising the compaction of the material

$$
\phi_{p}=\phi_{u}-\phi_{0}=\left(1-\phi_{0}\right)\left(1-\frac{1}{J^{p}}\right)
$$


where $\phi_{u}$ is the eulerian porosity of the unloaded state and $J^{p}$ is the determinant of the transformation $\boldsymbol{F}^{p}$. The effective stress is linked with pore pressure and total stress according to the equation

$$
\boldsymbol{\sigma}=\boldsymbol{\sigma}^{\prime}-b p \boldsymbol{I}
$$

with $b\left(\phi_{u}\right)$ the Biot coefficient (Biot, 1941). The effective stress evolution can be deduced from the Jaumann derivative (Bernaud et al., 2002)

$$
\frac{D_{J} \boldsymbol{\sigma}^{\prime}}{D t}=\dot{\boldsymbol{\sigma}}^{\prime}+\boldsymbol{\sigma}^{\prime} . \boldsymbol{\Omega}-\boldsymbol{\Omega} \cdot \boldsymbol{\sigma}^{\prime}=\mathcal{C}\left(\boldsymbol{d}-\boldsymbol{d}_{\boldsymbol{p}}\right)+\dot{\mathcal{C}}: \mathcal{C}^{-1} \boldsymbol{\sigma}^{\prime}
$$

where $\boldsymbol{d}$ and $\boldsymbol{d}_{\boldsymbol{p}}$ are the total and plastic strain rate tensors, $\boldsymbol{\Omega}$ is the spin rate tensor and $\mathcal{C}$ is the Hooke's tensor. The change in pore pressure therefore reads

$$
\dot{p}=M\left[-b \operatorname{tr}\left(\boldsymbol{d}-\boldsymbol{d}_{\boldsymbol{p}}\right)+\frac{\dot{\phi}-\dot{\phi_{p}}}{J^{p}}\right]+\frac{\dot{M}}{M} p-\operatorname{Mbtr}\left(\mathcal{C}^{-1}: \boldsymbol{\sigma}^{\prime}\right)
$$

with $M\left(\phi_{u}\right)$ the Biot modulus. In the present case, focusing on plastic strain, we assume $b\left(\phi_{u}\right)=1$ that results in Terzaghi effective stress and $\dot{b}=\dot{M}=0$. It is a strong assumption particularly when considering a loading path involving elastic unloading which is not the case in the present paper.

\subsection{Plastic behaviour}

A commonly used model to describe the plastic behaviour, especially the compaction of porous media, is the Drucker-Prager Cap model (DiMaggio and Sandler, 1971). This model has been widely used to describe the behaviour of geomaterials (DiMaggio and Sandler, 1971; Grueschow and Rudnicki, 2005) as well as in applications where the focus is on mechanical compaction such as powder compaction modelling (Garner et al., 2015; Perez-Gandarillas et al., 2017). This model has a yield surface made of a line corresponding to a Drucker-Prager model to describe shear plasticity and an ellipsoidal Cap to describe compaction plasticity. The yield surface for a given compacted state is plotted in figure 3 in red for shear plasticity and blue for the compaction. The yield surface associated with shear plasticity is defined by the following equation

$$
F_{s}=q-p^{\prime} \tan \beta-c
$$

where $\beta$ is the internal friction angle and $c$ the cohesion.

$$
p^{\prime}=-\frac{1}{3} \operatorname{tr}\left(\boldsymbol{\sigma}^{\prime}\right)
$$

is the mean effective stress, and

$$
q=\sqrt{\frac{3}{2} s: s}
$$


is the equivalent stress with the deviatoric stress $s=\boldsymbol{\sigma}^{\prime}+p^{\prime} \boldsymbol{I}$. The flow potential for the shear yield surface is based on a usual non-associated formulation

$$
G_{s}=\sqrt{\left[\left(p_{l}^{\prime}-p^{\prime}\right) \tan \beta\right]^{2}+q^{2}}
$$

where $p_{l}^{\prime}$ is the point on the $p^{\prime}$-axis that represents the transition between the shear and compaction yield surfaces. The compaction yield surface is a portion of an ellipse given by

$$
F_{c}=\sqrt{\left(p_{l}^{\prime}-p^{\prime}\right)^{2}+(r q)^{2}}-r\left(c+p_{l}^{\prime} \tan \beta\right)
$$

with $r$ a material parameter defining the cap shape. The flow potential corresponding to compaction is associated with the cap and therefore reads

$$
G_{c}=\sqrt{\left(p_{l}^{\prime}-p^{\prime}\right)^{2}+(r q)^{2}}-r\left(c+p_{l}^{\prime} \tan \beta\right) .
$$

In this framework, the hardening law is usually linking the volumetric plastic strain and the consolidation pressure $p_{c}^{\prime}$ that can be related to the parameter $p_{l}^{\prime}$ through the relation

$$
p_{c}^{\prime}=r c+p_{l}^{\prime}(1+r \tan \beta) .
$$

In the present work, in order to be able to provide results consistent with empirical geophysical law used to describe compaction in oedometric context, we consider a description of the hardening linking the consolidation pressure $p_{c}^{\prime}$ to the unloaded porosity $\phi_{u}$ introduced in the section 2.1. Therefore the unloaded porosity is in the present case a key variable characterising the state of the material with regard to its compaction. This choice is particularly relevant in basin modelling context where porosity is commonly considered as the parameter characterising compaction rather than plastic strain. A reason for that is that present day porosity can be observed through drilling, logging and experiments whereas plastic strain due to basin history cannot be measured. To recover a behaviour that can be compared with Schneider's law the hardening reads

$$
\phi_{u}=\phi_{r}+\phi_{a} e^{-p_{c}^{\prime} / p_{a}^{\prime}}+\phi_{b} e^{-p_{c}^{\prime} / p_{b}^{\prime}}
$$

where $p_{a}^{\prime}$ and $p_{b}^{\prime}$ are compaction parameters. For the case of Athy's compaction model, the relation defining the hardening can be written

$$
\phi_{u}=\phi_{0} e^{-\kappa^{\prime} p_{c}^{\prime}}
$$

with $\kappa^{\prime}$ a compaction parameter. This second form can be recovered from the previous one considering $\phi_{r}=\phi_{b}=0$ and $\kappa^{\prime}=1 / p_{a}^{\prime}$. In both cases, when the rock is in a virgin state $\left(\phi_{u}=\phi_{0}\right)$, the cap is such that $p_{b}^{\prime}=0$. The initial yield surface location can be deduced from figure 3 in which the initial cap location is shown in green. Therefore, for any stress change leading to an increase of the mean effective stress, the rock starts to compact as it is required to model the behaviour of virgin soil at the earliest stage of 
burial and to be consistent with empirical relationships. Indeed, virgin soil can be compacted even with stress increment that are very small compared to the stress increase seen by a rock that has been submitted to a burial of several hundreds of meters. Nevertheless the focus of basin modelling is usually on layers that are significantly buried (the first $200-500 \mathrm{~m}$ are not considered as key issues). The purpose of the proposed constitutive law is to provide a refined description of the compaction of deeply buried layers. A common issue when modelling the finite strain compaction plasticity of porous mediua is to choose a hardening law ensuring that the porosity will not become negative as compaction proceeds, as underlined by previous works (Deudé et al., 2004). It is clearly the case here for the hardening associated with Schneider compaction model when using a non zero residual porosity and it is usually the case for the hardening law linked with Athy compaction model if the elastic strain are small enough. To be sure to verify this condition, a formalism considering a residual porosity is clearly safer. It is to note that in many cases an intermediate hardening law can be used, it reads

$$
\phi_{u}=\phi_{r}+\left(\phi_{0}-\phi_{r}\right) e^{-\kappa^{\prime} p_{c}^{\prime}} .
$$

This law can be seen as a Athy's law with a residual porosity or as a Schneider's law with a single exponential. It is to note that relation 20 can be rewritten in the form

$$
p_{c}^{\prime}=-\frac{1}{\kappa^{\prime}} \ln \left(\frac{\phi_{u}}{\phi_{0}}\right)
$$

and the relation 21 leads to

$$
p_{c}^{\prime}=-\frac{1}{\kappa^{\prime}} \ln \left(\frac{\phi_{u}-\phi_{r}}{\phi_{0}-\phi_{r}}\right) .
$$

whereas no analytical form of the inverse of relation 19 is proposed herein.

\subsection{Elastic behaviour}

An isotropic elasticity tensor describing the elastic behavior of rocks is adopted, according to a simplifying assumption. The elasticity tensor is related to the bulk and shear modulus $K$ ans $G$ through the equation

$$
\mathcal{C}=(K-2 G / 3) \boldsymbol{I} \otimes \boldsymbol{I}+\mathcal{I}
$$

with $\boldsymbol{I}$ and $\mathcal{I}$ the second and fourth order identity tensors. The elastic properties of rocks are known to evolve with compaction. Here, we take this phenomenon into account by relating the elastic properties to the variable characterising compaction, the unloaded porosity $\phi_{u}$. The upper limit of HashinShtrikman (Hashin, 1983) is considered here such as in the work of Maghous et al. (2013). It leads to the bulk modulus

$$
K=\frac{4 K_{s} G_{s}\left(1-\phi_{u}\right)}{3 K_{s} \phi_{u}+4 G_{s}}
$$


and the shear modulus

$$
G=\frac{G_{s}\left(1-\phi_{u}\right)\left(9 K_{s}+8 G_{s}\right)}{K_{s}\left(9+6 \phi_{u}\right)+G_{s}\left(8+12 \phi_{u}\right)}
$$

where $K_{s}$ and $G_{s}$ are grain bulk and shear modulus.

\subsection{Comparison with empirical compaction laws}

In this section, the model presented hereabove is compared to Athy's and Schneider's empirical laws. For the comparison, the oedometric context is considered and we study the effect of an increase of vertical effective stress on an elementary volume with no horizontal displacements (oedometric conditions). In order to be able to recover results that can be compared with empirical laws in terms of porosity we have defined the plastic and elastic parameters considering two sets of typical values. The first set represents the behaviour of a sand and the second one the behaviour of a shale. The elastic parameters, the volumetric mass and the cohesion are given in table 2 with $K_{0}=K\left(\phi_{0}\right)$ and $G_{0}=G\left(\phi_{0}\right)$ the initial elastic properties. It is to note that elastic properties do not have a significant influence on the computation performed in this paper as we mainly focus on plastic compaction under Terzaghi hypothesis. Also, cohesion is not significantly influencing the results as we consider a rather small value compared to the magnitude of the mechanical loadings. We consider a rigid enough elastic behaviour for the condition of small elastic strain compared to plastic ones to be verified. We consider several values for the friction angle and $r$ parameter to demonstrate the model ability to recover results consistent with empirical laws. The tested configurations are listed in table 3. We relate the compaction hardening parameter values to those of the empirical laws. With Athy's compaction model we consider the relation

$$
\kappa^{\prime}=\frac{\kappa}{\xi}
$$

and with Schneider's compaction model

$$
p_{i}^{\prime}=\xi \sigma_{i}
$$

where $i$ stands for $a$ or $b$. To provide a relevant approximation of empirical laws the parameter $\xi$ can be deduced from the previously defined $r$ and $\tan (\beta)$ with the relation

$$
\xi=\frac{1+\tan (\beta) \frac{3 r^{2}}{\sqrt{4+3 r^{2}}} .}{1+\tan (\beta) r} .
$$

Parameters of the empirical compaction laws are defined to describe the behaviour of a sand and of a shale. The Schneider's parameters are issued from the TemisFlow (2017) default material parameter library. Athy's parameters are defined by the authors to model approximately the same material. Porosity versus effective stress curves used in this paper are plotted on figure 4 in the 
case of a drained material and vertical effective stress $\sigma_{z z}^{\prime}=\sigma_{e f f}$. As shown in figure 4 the Athy's compaction law does not allow to recover exactly the same behaviour as the Schneider's compaction law. Especcially for the case of a shale were the Athy's law does not allow to have the same curvature or residual porosity. The compaction parameters are detailed in table 1 .

We first focus on Athy's compaction model for sand and shale. The results of an oedometric loading are shown in figure 5,6 and 7. The porosity results from Athy's empirical scalar model are compared to the results of the tensorial model for the five sets of yield surface parameters and the two materials, sand (figure 5(a)) and shale (figure 5(b)). There is a very good agreement between the original compaction model of Athy and its present version in terms of porosity for each considered case as the difference is lower than 0.001 for the studied effective stresses. It is to note that the porosities of the present model are almost equal to the unloaded porosities as the elastic strains are very small compared to plastic ones.

The ratio between the horizontal and vertical effective stress is plotted for the present model simulations in figure 6(a) for the sand and in figure 6(b) for the shale. Even if the results are almost the same in terms of porosity whatever the values of $r$ and $\tan (\beta)$ are, the results in terms of horizontal effective stress are significantly different as shown in figure 6 . The tendencies are the same for sand and shale. The ratio between horizontal and vertical effective stresses quickly increases with the increase of vertical stress and stabilise for a given vertical effective stress. For a given vertical effective stress, the horizontal effective stress increases with $r$ and decreases with $\tan (\beta)$. Calculated effective stress ratio are in line with the observations reported by Breckels and van Eekelen (1982) analysing the effective stress ratio with depth observed tendencies and empirical laws. Calculated effective stress ratio are also relevant for layers below a depth of 500 meters according to the work of Plumb (1994) based on a multi-basin analyses of total stresses. According to the author, for superficial layers, higly compressive stress state can be observed in some particular basin where thrust faulting appears in the upper part of the basin and changes to a normal or strike-slip faulting environment at greater depth. Of course, such phenomena are not considered here, the studied case being oedometric. Whatever considered parameters, the results in terms of horizontal stresses for close to ground level layers may or may not be adequate as physical phenomena neglected here can be involved. As already pointed out this is not the main concern in basin modelling which usually focuses on layers buried at more than 200-500 meters.

The stress paths in the $p^{\prime}-q$ plane are plotted in figures 7 (a) for the sand and 7 (b) for the shale. We can observe that the stress path is almost linear for every case. The stress state is such that no shear plasticity occurs. The stress path for the scenarii (1) in the $p^{\prime}-q$ plane are plotted in figures 7 (c) for the sand and $7(\mathrm{~d})$ for the shale along with shear plasticity limit and cap for different time step in red. As shown in figures 7(c) and 7(d), the stress path is such that the shear plastic limit is not reached. Furthermore stress path linearity is justified by the fact that the direction of the normal to the cap for 
the reached $p^{\prime}-q$ does not evolve significantly during compaction. Both mean effective stress and equivalent stress increase with the loading and for a given mean effective stress. The equivalent stress is higher with $r$ decreasing and with $\tan (\beta)$ increasing. A slight increase of the $q$ to $p^{\prime}$ ratio can be observed in the case of shale as suggested by the results plotted in figure 6(b).

We perform the same test for the Schneider's scalar compaction model and for its present version. The results are plotted the same way in figure 8, 9 and 10. As for Athy's empirical law, the results in terms of porosity are consistent between the scalar law of Schneider and the present law (see figures 8(a) for the sand and 8(b) for the shale).

The tendencies observed in figure 6 for Athy's compaction model can also be observed for the compaction model of Schneider in figure 9 . The horizontal to vertical effective stress ratio depends on both $r$ and $\tan (\beta)$. In every case it starts to increase with the load and then stabilises to a value which is higher when $r$ increases and $\tan (\beta)$ decreases.

For the Schneider's compaction model, stress paths in the $p^{\prime}-q$ plane for the different tested configurations (see table 3 ) lead to an almost linear evolution of $q$ with $p^{\prime}$ for both sand and shale as shown in figures 10(a) and 10(b). These results are similar to the results obtained with the Athy's compaction model and the result plotted in figures 10(c) and 10(d) are consistent with the results shown in figures $7(\mathrm{c})$ and $7(\mathrm{~d})$.

\section{Numerical hydro-mechanical modelling}

In this section, numerical simulations coupling basin modelling and geomechanics with respect to the framework presented in the section 2 are performed to describe the sedimentation of geological columns considering a single material, sand or shale, for each case. The objective of this section is to illustrate the ability of the proposed rheology to describe the behaviour of the porous medium in a tectonic loading context and to evaluate the effect of a tectonic compressive loading on the in situ stress, pore pressure and porosity. We are here focusing on the effect of past tectonic phases and on their effect on the actual and observable state of the column corresponding to the final state of the computation. In all cases we consider the hardening law reproducing the behaviour of Schneider's compaction model in the oedometric context (19). The test cases focus on the effect of different tectonic loadings leading to various horizontal strain rates and occuring at different times during the sedimentation process.

The coupled simulations are perfomed using a prototype code named $\mathrm{A}^{2}$. This simulator is based on a sequential coupling of the finite volume basin simulator ArcTem (Faille et al., 2014) and the finite element geomechanical simulator Code_Aster (2017) performed using an iterative algorithm (Guy et al., 2013). In the present case the same grid is used for both simulators. The finite strain is taken into account considering an updated lagrangian approach. 
In order to model the effect of compaction on permeability several relationships (Doyen, 1988; Yang and Aplin, 2010) can be used and have been tried along within the present framework. For the sake of simplicity, we consider here a commonly used relation which is a modified version of KozenyCarman (Kozeny, 1927; Carman, 1939) relation. We assume a diagonal permeability tensor $\boldsymbol{k}$ in cartesian coordinates $(x, y, z)$ with $z$ corresponding the vertical direction, considered as normal to lithification. Its diagonal components associated with the three directions $(x, y, z)$ are respectively $k_{h}, k_{h}$ and $k_{v}$. We therefore consider this tensor as transversely isotropic in such a way that $k_{v}=\alpha k_{h}$ with $\alpha$ the anisotropy coefficient of the permeability tensor. The evolution of horizontal permeabiliy is linked with the porosity of the unloaded state through the relation

$$
k_{h}=\frac{0.2 \phi_{u}^{3}}{s_{0}^{2}\left(1-\phi_{u}\right)^{2}}
$$

with $s_{0}$ the specific surface.

\subsection{Test cases}

We are considering an horizontally infinite domain in which a sedimentation of flat geological layers occur in a first phase. In a second phase, a tectonic loading leading to an homogeneous horizontal and unidirectional strain of the considered domain is added to the sedimentation. Taking advantage of the symmetries of the horizontally infinite domain and associated tectonic loading, we reduce the geometry to a single column of elements. Two sets of loading history and two kinds of material are studied. A scheme of the modeled cases is shown in figure 11. During sedimentation the elements are added one by one, every million years during 100 million years, as described in the figure 11 . The elements are hexahedra with an initial horizontal section being square of 100 meters sides before any tectonic phase. The horizontal section of deposing elements is equal to the horizontal section of underlying elements during and after tectonic phases. The elements have a thickness of 100 meters at deposition. The sedimentation process is modelled by a progressive increase of solid density of deposing element $\rho_{s}$ from zero to the precribed value. The modeled sedimentation rate is therefore of 100 meters per million years. In the present analysis we will focus on the first 4000 meters of sediment from the surface because it is where mechanical compaction usually dominates (Hedberg, 1936). The fluid flow boundary conditions are no flux conditions for every bounds except for the top of the column where pore pressure is set to zero. It is the case for both sedimentation only and tectonic phases. For the mechanical boundary conditions, the upper boundary is free and the normal displacements are blocked for the other bounds. Therefore, the sedimentation leads to an oedometric loading of the underlying layers as for the three first states of the figure 11. For the tectonic phases, the horizontal displacements on the lateral bounds are prescribed so as to reach a given state of horizontal 
strain in the $x$ direction while the displacements in the $y$ direction are set to zero for every boundary. It is to note that in the present computations sedimentation is continuous and does not stop during tectonic phases as suggested by the schemes of column geometry of the figure 11 . In this schemes, the tectonic loading takes place between the third and fourth described geometry leading to both an horizontal shortening of the column and a sedimentation. Some simulations are performed without tectonic loading in order to make comparisons. Applied tectonic loadings lead to a horizontal shortening of $5 \%$ in every case, nevertheless we study several tectonic loading configurations through changing the duration of the tectonic phase and its starting time. For every scenario we study the effect of tectonic on sand or shale columns considering the parameters listed in the table 2. After this, the results of the coupled framework are compared with the results of an uncoupled basin model (ArcTem in the present case).

\subsection{Results}

For all the figures and analyses in this section we consider the geological sign convention for stresses leading to positive values for compression. In a first set of simulations the effect of the tectonic phase duration is studied. Four scenarios are compared. In the first one no tectonic loading is applied. In the other ones the tectonic loading is applied during the last 5, 10 and 15 million years of sedimentation leading to different imposed horizontal strain rates. Then, a second set of simulations focus on the effect of the age of the tectonic phase. In this set a simulation with no tectonic loading applied is compared to three simulations in which a 5 million years tectonic phase is modeled starting 5, 10 and 15 million years before the present state (the final state of the simulation).

\subsubsection{Effect of the duration of tectonic phase}

Calculated stresses and pore pressure are related to the hydrostatic pore pressure and are plotted in figure 12. Porosities and vertical permeabilities are shown in figure 13. Pore pressure and vertical total stress at present state (or final state of the computation) are plotted in figure 12(a) for sand and in figure 12(b) for shale. For the sand column, there is no overpressures whatever the case whereas for the shale column, significant overpressures (between 100 and 300 bars at depth greater than 2000 meters) due to compaction disequilibrium (Magara, 1978; Mouchet and Mitchell, 1989) can be observed even for the case where no tectonic loading is applied. Furthermore, for the shale column, the overpressures are lower for lower horizontal strain rates as the overpressures can dissipate when the tectonic phase duration is longer. It is to note that even in the case of shale and in presence of tectonics, there are almost no overpressures above a depth of 1000 meters. 
The vertical total stress is not significantly modified by tectonic loading. The tectonic phase duration has almost no effect on the total effective stress for the present state. The results in terms of horizontal stresses can be seen in figure 12(c) and figure 12(e) for the sand column and in figure 12(d) and figure $12(\mathrm{f})$ for the shale column. As it can be seen in figure 12(d), for every scenario with tectonic loading, a horizontal strain of only $5 \%$ is enough to make the maximum horizontal stress become the maximum stress in shales buried below a depth of 2000 meters. In the sand column (figure 12(c)), the same effect can be observed with the highest strain rates. It is to note that the maximum horizontal stress is more affected by the decrease of horizontal strain rate in the case of sand than in the case of shale. Concerning the superficial layers above a depth of 500-1000 meters, there are almost no effect of the tectonic loading on the stress state. Calculated horizontal stresses (figure 12(e) for the sand and figure 12(f) for the shale) exhibit the same tendencies as maximum horizontal stresses.

The porosity and vertical permeability at the present state are shown in figure 13(a) and 13(c) for the sand column and figure 13(b) and 13(d) for the shale column. The present porosity of the shales is almost not modified by the tectonic loading whereas the porosity of the sand is influenced, especially when the horizontal strain rate is high. The decrease of sand porosity is induced by the tectonic loading surperimposing to the vertical mechanical loading due to sedimentation. The tectonic loading leads to a significant plastic compaction in the case of sand, when the overpressures disspate because of high permeability. Indeed, in the case of shale, the porosity change is lower and the pore pressure change is higher than in the case of sand because the permeability is lower and do not allow the overpressure to dissipate in the considered times. This is what happens with compaction disequilibrium, when the generated overpressure leads to a preservation of the porosity (Magara, 1978; Mouchet and Mitchell, 1989). Therefore, according to this simulation, when analysing present state, the pore pressure and stress state exhibit a clear signature of past tectonic events for shales, nevertheless the porosity and vertical permeability are not influenced. For the sands, the stress state and the porosity are modified by tectonics but the pore pressure is still hydrostatic.

\subsubsection{Effect of the age of tectonic phase}

The ratio of stress and pore pressure to hydrostatic pore pressure are plotted in figure 14. As shown in figure 14(a) the pore pressure is hydrostatic for the case of sands even with tectonic loading. The effect of tectonic loading on vertical stress is not significant and every tectonic case lead to almost the same vertical stress. The result in terms of vertical stress are of the same kind for the shale column (figure 14(b)) and are closed to the results plotted in figure 12(b). With tectonic loading the pore pressure increase is significant in the case of shale nervertheless the pore pressure rise decreases significantly with the age tectonic phases. For the case with the oldest tectonic loading, the overpressures have almost vanished for layers above a depth of 3000 meters. Even for the 
case of a tectonic phase begining 10 million years before the present state and ending 5 million years before the actual state, the overpressures have almost disappeared for layers above 2500 meters deep.

The ratio of horizontal maximum stress to hydrostatic pore pressure is plotted for sand and shale in figures 14(c) and 14(d). The ratio of horizontal minimum stress to hydrostatic pore pressure is plotted for sand and shale in figures 14(e) and 14(f) respectively. As for the set of case focusing on tectonic phase duration, the effect of tectonics on horizontal stress is very clear, but it decreases more with the age of tectonic phase than with its duration. As an example for a shale located at a depth of 3000 meters, the contribution of the tectonic phase to maximum horizontal stress is reduced by about one third when its starting age changes from 5 million years to 10 million years before the present state. For the same shale, the contribution of the tectonic phase to overpressure is reduced by about three fourth when its starting age changes from 5 million years to 10 million years before the present state. It appears that the effect of older tectonic loading phases can be observed more clearly analysing stress than analysing overpressures.

Concerning the porosity and vertical permeability, they are weakly modified for the case of shales (figure 15(b) and 15(d)) as in the previous set of simulations shown in figure 13(b) and 13(d). An influence of tectonic loading can be seen for sand (figure 15(a) and 15(c)) and once more the effect of tectonic loading on the present state is significantly decreased when the age of the tectonic phase increases. Indeed, the sedimentation continuing after the older tectonic phase leads to additionnal compaction of buried layers and erase the porosity and vertical permeability change due to the tectonic strain. Nevertheless a significant change in the porosity of sandstone can be induced by late tectonic loadings.

\subsubsection{Effect of the age of tectonic phase}

The ratio of stress and pore pressure to hydrostatic pore pressure are plotted in figure 16 for both the coupled approach and for an uncoupled basin modelling approach (here based on ArcTem). As shown in figure 16(a) the pore pressure is hydrostatic for the case of sands even with tectonic loading and for any modelling tool. The effect of tectonic loading on vertical stress is not significant and every tectonic case lead to almost the same vertical stress. The result in terms of vertical stress are of the same kind for the shale column (figure 16(b)). Nevertheless the results in terms of pore pressure are very different between the coupled and uncoupled approaches with tectonic loading (figure 16(b)). The uncoupled approaches completely miss the overpressure build up induced by the tectonic loading. This pressure build up only appears when using a tools that include a tensorial description of geomechanics. 


\section{Conclusions}

A framework to model basin history along with geomechanics has been presented and a Drucker-Prager Cap model dedicated to the modelling of three dimensionnal compaction of rock has been proposed. This model can be seen as a present extension of the widely used Athy's and Schneider's compaction law and has been used with the prototype simulator $\mathrm{A}^{2}$. The constitutive law has been built to reproduce respectively Athy and Schneider compaction models in oedometric conditions and could be extended to reproduce other compaction models. With the framework presented herein, present day pore pressure and stresses can be characterised considering properly the effect of past tectonics. For both empirical compaction law envisionned, the DruckerPrager Cap relies on an original hardening function linking the porosity to consolidation pressure. The proposed hardening allows to recover the results of the two empirical laws in terms of porosity as it has been shown studying oedometric compaction. Furthermore the proposed model allows to evaluate horizontal stresses and to take into account the effect of tectonics and stress redistribution on the in situ stress state and pore pressure through coupled analysis. Therefore, the proposed framework provide an estimation of key parameters to characterise rock compaction and natural fracturing.

The presented framework has been used to perform coupled simulations of sedimentation along with different sets of tectonic loading. The effect of tectonic phase age and duration have been studied considering typical properties of sand or shale. These computations have led to the conclusion that the tectonic loading, even for relatively weak horizontal strain (only 5\%) and reasonable strain rate (from 0.3 to $1 \%$ each million years) can lead to significant overpressures (several hundreds of bars below a depth of 2000 meters). Indeed, it has been the case when shale properties were considered whereas no overpressures have been observed for the cases based on sand properties. Also, tectonic loadings has led to significant change in stress regime for both sand and shale, vertical stresses being only weakly influenced, the horizontal stress commonly being higher than the vertical stress after tectonic strain (with the geological sign convention). The effect of past tectonic loadings on pore pressure has appeared to be strongly decreased after only 5 million years whereas the effect of tectonics on stress state decreased more slowly in the computation, its decrease being linked with sedimentation. Also, the coupled framework studied herein has been compared to uncoupled basin modelling on a simple case. This comparison has shown that the uncoupled modelling does not describe the overpressures that can be induced by tectonics especially when shale are present. The proposed framework can be used to model more complex geological configurations. It is to note that it is common in practical application to define the initial state of stress and pore pressure without integrating basin history. The present framework has both shown that basin tectonic history can have a significant influence on present day state, and that a coupled approach based on basin modelling and geomechanics can be used 
to define a consistent present day stress state and pore pressure taking into account a basin tectonic history.

Acknowledgements This work was funded by the NOMBA project. 


\section{References}

Adjukiewicz JM, Lander RH (2010) Sandstone reservoir quality prediction: The state of the art. AAPG Bulletin 94:1083-1091.

Athy LF (1930) Density, porosity and compaction of sedimentary rocks. AAPG Bulletin 14:1-24.

Bernaud D, Deudé V, Dormieux L, Maghous S, Schmitt DP (2002) Evolution of elastic properties in finite poroplasticity and finite element analysis. Int J Num Anal Meth Geomech 26:845-871.

Bernaud D, Dormieux L, Maghous S (2006) A constitutive and numerical model for mechanical compaction in sedimentary basins. Comp geoth 33:316-329.

Biot MA (1941) General theory of three-dimensional consolidation. J Appl Phys 12:155-164.

Bourgeois E (1997) Mécanique des milieux poreux en transformation finie : formulation des problèmes et méthodes de résolution. Thèse de l'Ecole Nationale des Ponts et Chaussées.

Breckels IM, van Eekelen HAM (1982) Relationship between horizontal stress and depth in sedimentary basins. J Pet Tech 34:2191-2199.

Brüch A, Maghous S, Ribeiro FLB, Dormieux L (2018) A thermo-poromechanical constitutive and numerical model for deformation in sedimentary basins. J Pet Sci Eng 160:313-326.

Carman PC (1939) Permability of saturated sands, soils and clays. J Agricult Sci 93:7729-7740.

Code_Aster (2017) http://www.code-aster.org. EDF R\&D.

Coussy O (1991) Mécanique des milieux poreux. Edition Technip, Paris.

Debernardi D, Barla G (2009) New viscoplastic model for design analysis of tunnels in squeezing conditions. Rock Mech Rock Eng 42:259-288.

Deudé V, Dormieux L, Maghous S, Barthélémy JF, Bernaud D (2004) Compaction process in sedimentary basins: the role of stiffness increase and hardening induced by large strains. Int J Num Anal Meth Geomech 28:1279-1303.

DiMaggio FL, Sandler IS (1971) The effect of strain rate on the constitutive equation of rocks. Defense nuclear agency $2801 \mathrm{~T}$.

Doyen PM (1988) Permability, conductivity, and pore geometry of sandstone. J Geophys Res 93:7729-7740.

Faille I, Thibaut M, Cacas MC, Havé P, Willien F, Wolf S, Agelas L, PegazFiornet S (2014) Modeling fluid flow in faulted basins. Oil Gas Sci Tech 69:529-553.

Garner S, Strong J, Zavaliangos A (2015) The extrapolation of the DruckerPrager/Cap material parameters to low and high relative densities. Powder Technol 283:210-226.

Giles MR (1991) Diagenesis : A quantitative perspective. In: Implications for Basin Modelling and Rock Property Prediction. Kluwer Academic Publishers.

Grueschow E, Rudnicki JW (2005) Elliptic yield cap constitutive modeling for hig porosity sandstone. Int J Sol Struct 42:4574-4587. 
Guilmin AL (2012) Contribution de la mécanique à l'étude des bassins sédimentaires : modélisation de la compaction chimique et simulation de la compaction mécanique avec prise en compte d'effets tectoniques. Thèse de l'Université Paris-Est.

Guy N, Enchéry G, Renard G (2013) Numerical modeling of thermal EOR: comprehensive coupling of an AMR-based model of thermal fluid flow and geomechanics. Oil Gas Sci Tech 67:1019-1027.

Hantschel T, Kauerauf AI (2009) Fundamentals of basin and petroleum systems modeling. Springer-Verlag, Berlin Heidelberg.

Hashin Z (1983) Analysis of composite materials - a survey. J Appl Mech 50:485-505.

Hedberg HD (1936) Gravitational compaction of clays and shales. Am J Sci 31:241-287.

Houseknecht DW (1984) Influence of grain size and temperature on intergranular pressure solution, quartz cementation, and porosity in a quartzose sandstone. J Sedim Pet 54:348-361.

Houseknecht DW (1988) Intragranular pressure solution in four quartzose sandstones. J Sedim Pet 58:228-246.

Kozeny J (1927) Ueber kapillare Leitung des Wassers im Boden. Sitzungsber Akad Wiss 136:271-306.

Luo X, Pouya A, Lamoureux-Var V, Poliakov A, Vasseur G (1998) Elastoplastic deformation of porous media applied to the modelling of the compaction at the basin scale. Mar Pet Geol 15:145-162.

Luo X, Vasseur G (2002) Natural hydraulic cracking: Numerical model and sensitivity study. Earth Planet Sci Let 201:431-446.

Ma J (2017) An elasto-viscoplastic model for soft porous rocks within the consistent framework. Rock Mech Rock Eng 50:3109-3114.

Magara K (1991) Compaction and Fluid Migration: Practical Petroleum Geology. Elsevier Science, Amsterdam.

Maghous S, Brüch A, Bernaud D, Dormieux L, Braun L (2013) Twodimensional finite element analysis of gravitational and lateral driven deformation in sedimentary basins. Int J Anal Meth Geomech 38:725-746.

Coussy O (1991) Mécanique des milieux poreux. Edition Technip, Paris.

Obradors-Prats J, Rouainia M, Aplin AC, Crook AJL (2017) Assessing the implications of tectonic compaction on pore pressure using a coupled geomechanical approach. Mar Pet Geol 79:31-43.

Ouraga Z, Guy N, Pouya A (2017) Modeling of natural fracture initiation and propagation in basin sedimentation context. J Geophys Res Solid Earth 122:247-261.

Ouraga Z, Guy N, Pouya A (2018) Effect of hydro mechanical coupling on natural fracture network formation in sedimentary basins. Geophys J Int 213:798-804.

Perez-Gandarillas L, Mazor A, Lecoq O, Michrafy A (2017) Compaction properties of dry granulated powders based on Drucker-Prager Cap model. Powder Technol In Press.

Plumb RA (1994) Variations of the least horizontal stress magnitude in sedi- 
mentary rocks. In proceedings of $1^{\text {st }}$ North American Rock Mechanics Symposium, 1-3 June, Austin, Texas.

Schneider F, Potdevin JL, Wolf S, Faille I (1996) Mechanical and chemical compaction model for sedimentary basin simulators. Tectonophys 263:307313.

Schneider F, Hay S (2001) Compaction model for quartzose sandstones application to the Garn Formation, Haltenbanken, Mid-Norvegian Continental Shelf. Mar Pet Geol 18:833-848.

Secor D (1969) Mechanisms of natural extension fracturing at depth in the Earth's crust. Geol Surv Can Pap 68:3-48.

Sibson R (2003) Brittle failure controls on maximum sustainable overpressure in different tectonic regimes. AAPG Bull 87:901-908.

Smith JE (1971) The dynamics of shale compaction and evolution of pore fluid pressure. Math Geol 3:239-263.

Sulem J, Panet M, Guenot A (1987) An analytical solution for time-dependent displacements in a circular tunnel. Int J Rock Mech Min Sci 24:155-164.

TemisFlow (2017) http://www.beicip.com. Beicip-Franlab.

Terzaghi K (1923) Die berechnung der DuerchlÃơssigkeitsziffer des Tones in Verlauf der hydrodynamischen Spannungserscheinungen. Szber Akademie Wissenschaft Vienna Math-naturwissenshaft Klasse 132:125-138.

Wasantha PLP, Ranjith PG, Zhao J, Shao SS, Permata G (2015) Strain rate effect on the mechanical behaviour of sandstones with different grain sizes. Rock Mech Rock Eng 48:1883-1895.

Woillez MN, Souque C, Rudkiewicz JL, Willien F, Cornu T (2017) Insights in fault flow Behaviour from onshore Nigeria petroleum system modelling. Oil Gas Sci Tech 72:31-42.

Yang AY, Aplin AC (2010) A permeability-porosity relationship for mudstones. Mar Pet Geol 8:1692-1697. 
Table 1 Compaction parameters considered for Athy's and Schneider's law.

\begin{tabular}{|l||c|c|c|c|c|c|c|}
\hline Rock type & $\phi_{0}$ & $\kappa \mathrm{MPa}^{-1}$ & $\phi_{r}$ & $\phi_{a}$ & $\phi_{b}$ & $\sigma_{a} \mathrm{MPa}$ & $\sigma_{b} \mathrm{MPa}$ \\
\hline Sand & 0.46 & 0.0213 & 0.05 & 0.20 & 0.21 & 37. & 37. \\
\hline Shale & 0.65 & 0.0555 & 0.04 & 0.12 & 0.40 & 1. & 14. \\
\hline
\end{tabular}

Table 2 Mechanical and tranfer parameters of the modeled rocks.

\begin{tabular}{|l||c|c|c|c|c|c|}
\hline Rock type & $K_{0}(\mathrm{GPa})$ & $G_{0}(\mathrm{GPa})$ & $c(\mathrm{MPa})$ & $\rho_{s}\left(\mathrm{~kg} \cdot \mathrm{m}^{-1}\right)$ & $s_{0} \mathrm{~m}^{2}$ & $\alpha$ \\
\hline Sand & 4. & 2. & 1. & 2675. & $5.10^{5}$ & 1. \\
\hline Shale & 4. & 2. & 1. & 2645. & $5.10^{7}$ & 0.01 \\
\hline
\end{tabular}

Table 3 Configuration tested for $\tan (\beta)$ and $r$.

\begin{tabular}{|l||c|c|c|c|c|}
\hline Parameter & $(1)$ & $(2)$ & $(3)$ & $(4)$ & $(5)$ \\
\hline$r$ & 1.0 & 0.75 & 1.25 & 1.0 & 1.0 \\
\hline $\tan (\beta)$ & 1.0 & 1.0 & 1.0 & 0.667 & 1.333 \\
\hline
\end{tabular}




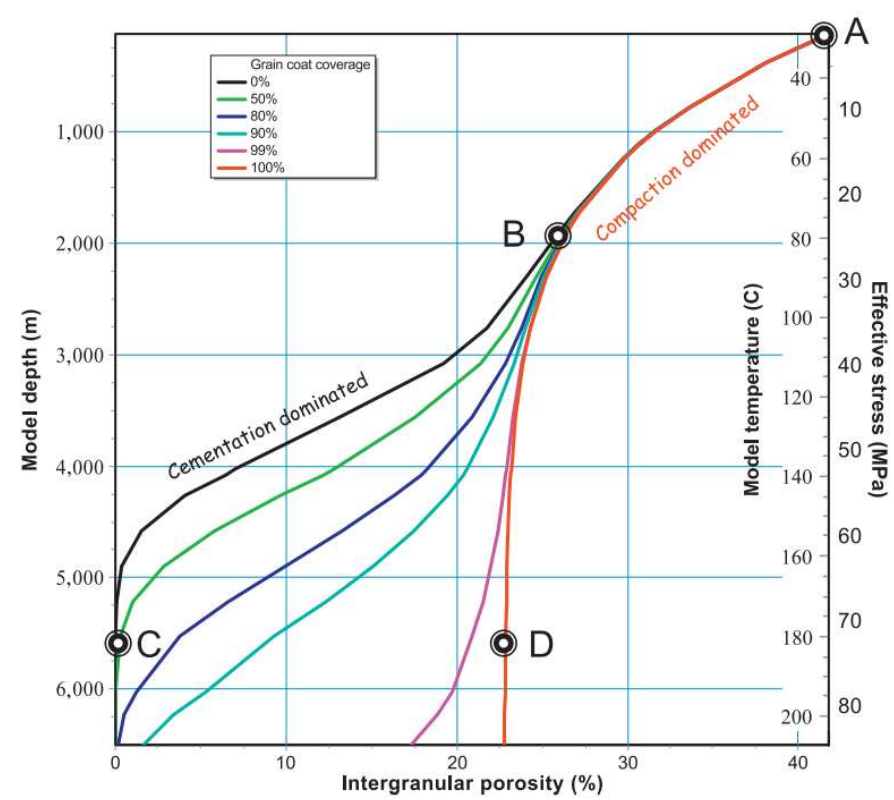

Fig. 1 Porosity-depth curves and key phenomena from Adjukewicz \& Lander (Adjukiewicz and Lander, 2010).

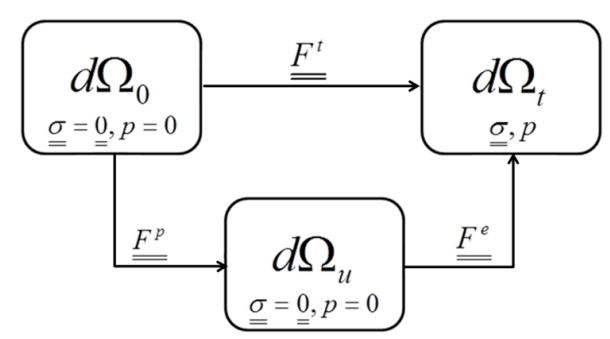

Fig. 2 Scheme of the different poromechanical state and transformations.

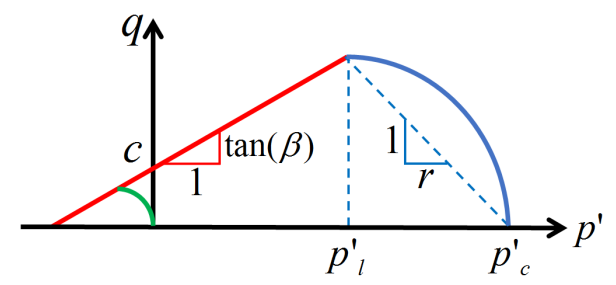

Fig. 3 Description of the yield surfaces in the $p^{\prime}-q$ plane, the red line correspond to the shear plasticity limit, the green curve to the initial cap and the blue curve to the cap after compaction. 


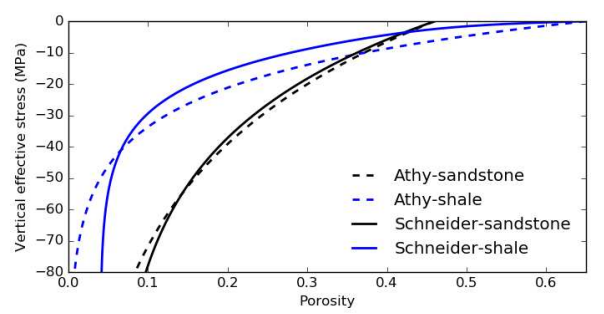

Fig. 4 Porosity versus vertical effective stress for the original compaction models of Athy and Schneider for a sand and a shale.
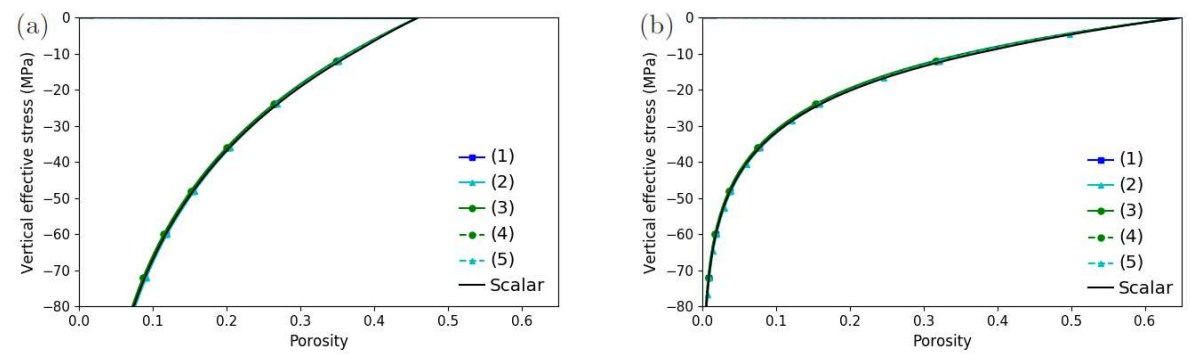

Fig. 5 Porosity versus vertical effective stress for the original compaction model of Athy and for its present version for different $r$ and $\tan (\beta)$ (see table 3) considering a sand (a) and a shale (b).
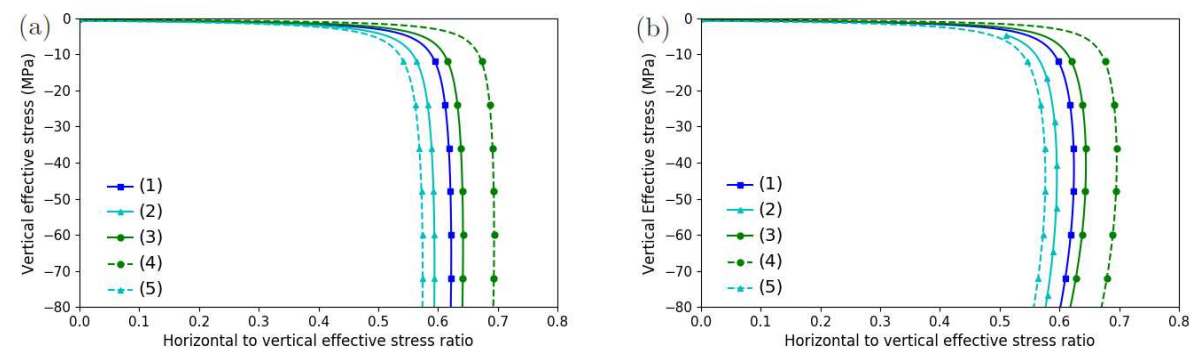

Fig. 6 Ratio of horizontal and vertical effective stress versus vertical effective stress for the present compaction model of Athy for different $r$ and $\tan (\beta)$ (see table 3) considering a sand (a) and a shale (b). 

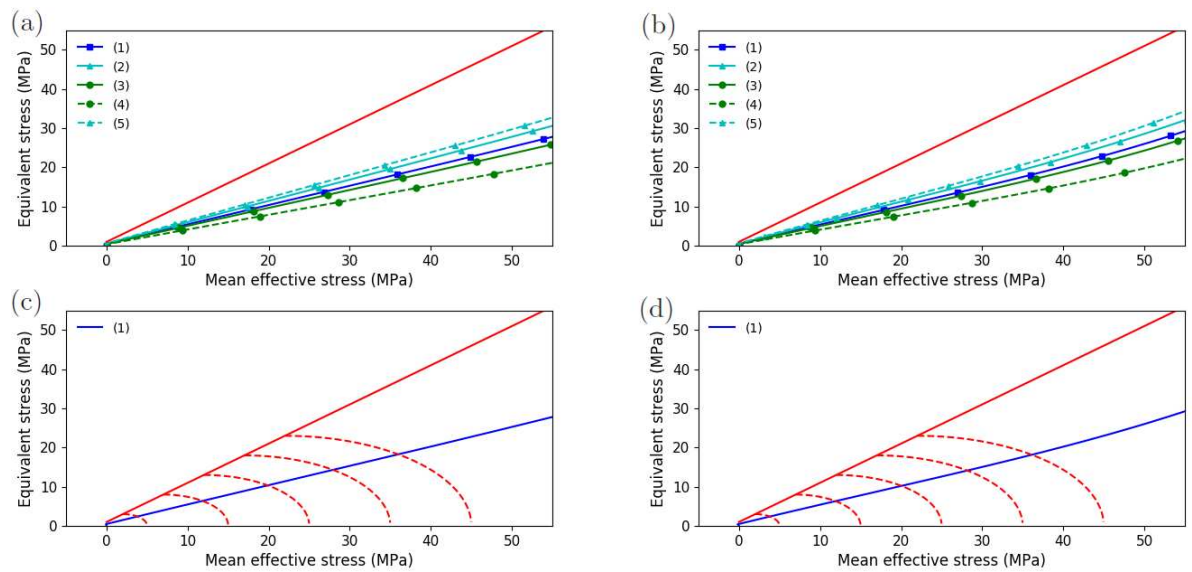

Fig. 7 Stress path in the $p^{\prime}-q$ plane for the present compaction model of Athy for different $r$ and $\tan (\beta)$ (see table 3 ) considering a sand (a) and a shale (b) along with the shear plasticity limit given by $c=1.0 \mathrm{MPa}$ and $\tan (\beta)=1.0 \mathrm{in}$ red, and stress path in the $p^{\prime}-q$ plane for the present compaction model of Athy for one scenario along with associated shear plasticity limit in red and several cap corresponding different state in red dashed lines for sand (c) and shale (d).
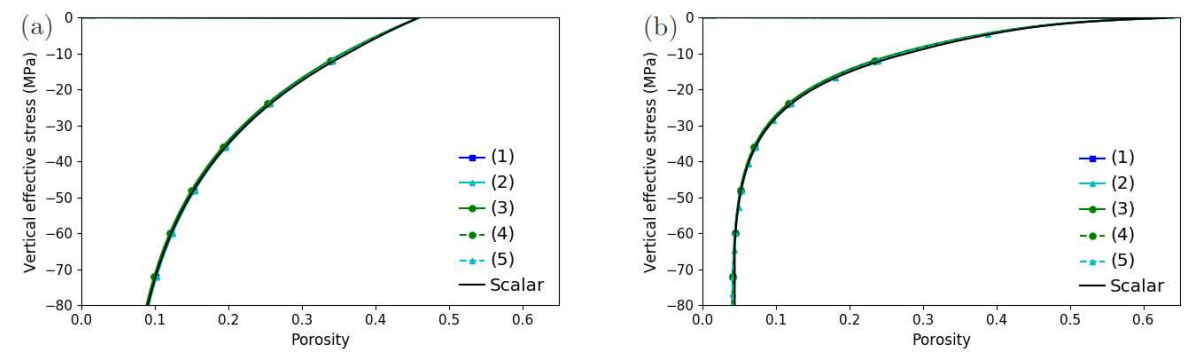

Fig. 8 Porosity versus vertical effective stress for the original compaction model of Schneider and for its present version for different $r$ and $\tan (\beta)$ (see table 3) considering a sand (a) and a shale (b).
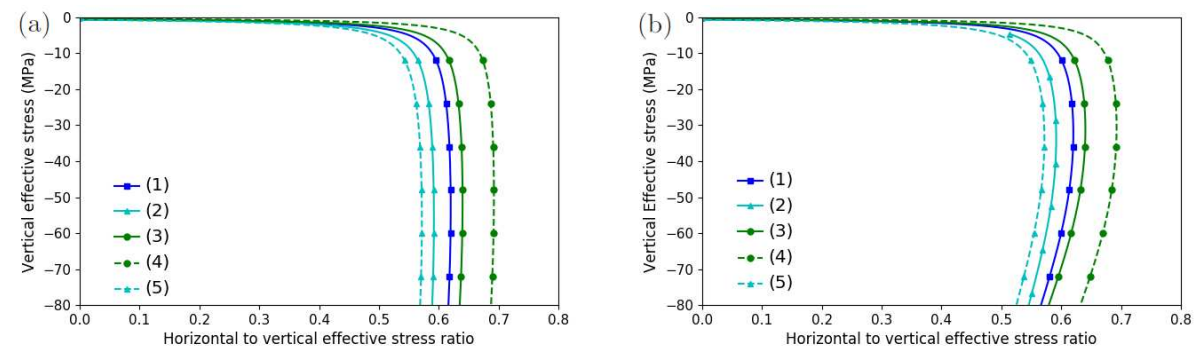

Fig. 9 Ratio of horizontal and vertical effective stress versus vertical effective stress for the present compaction model of Schneider for different $r$ and $\tan (\beta)$ (see table 3) considering a sand (a) and a shale (b). 

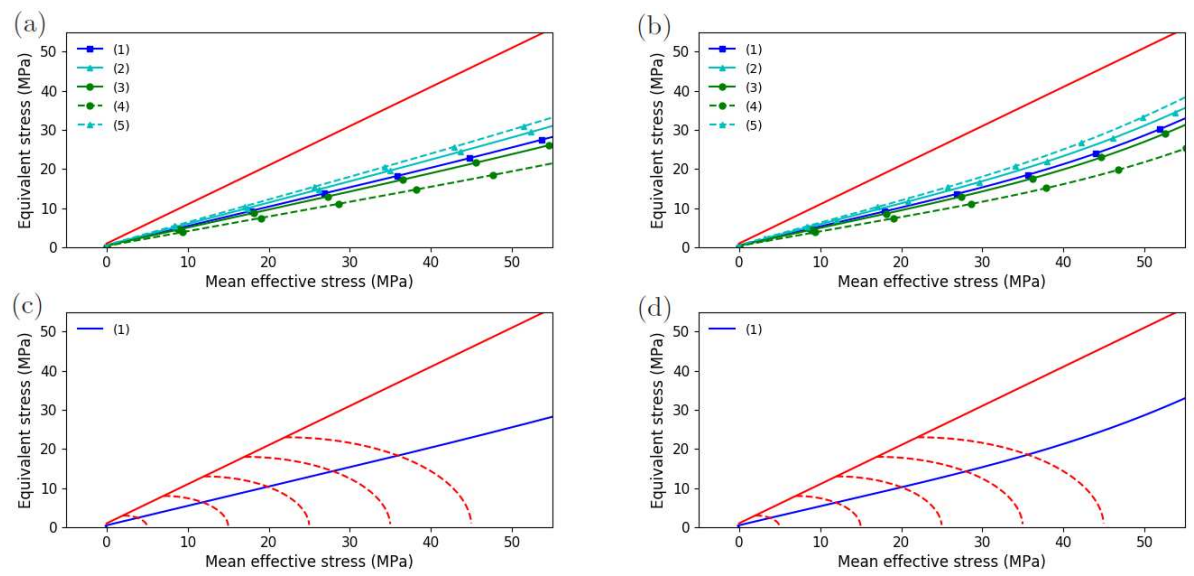

Fig. 10 Stress path in the $p^{\prime}-q$ plane for the present compaction model of Schneider for different $r$ and $\tan (\beta)$ (see table 3) considering a sand (a) and a shale (b) along with the shear plasticity limit given by $c=1.0 \mathrm{MPa}$ and $\tan (\beta)=1.0$, and stress path in the $p^{\prime}-q$ plane for the present compaction model of Athy for one scenario along with associated shear plasticity limit in red and several cap corresponding different state in red dashed lines for sand (c) and shale (d).

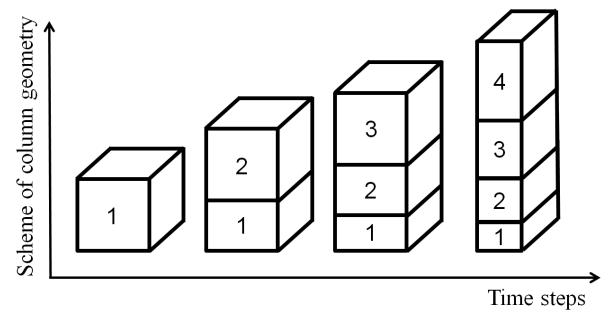

Fig. 11 Scheme of the columpn geometry evolution layers numbered according to their sedimentation order with four period of sedimentation, tectonic is active in the fourth period. 

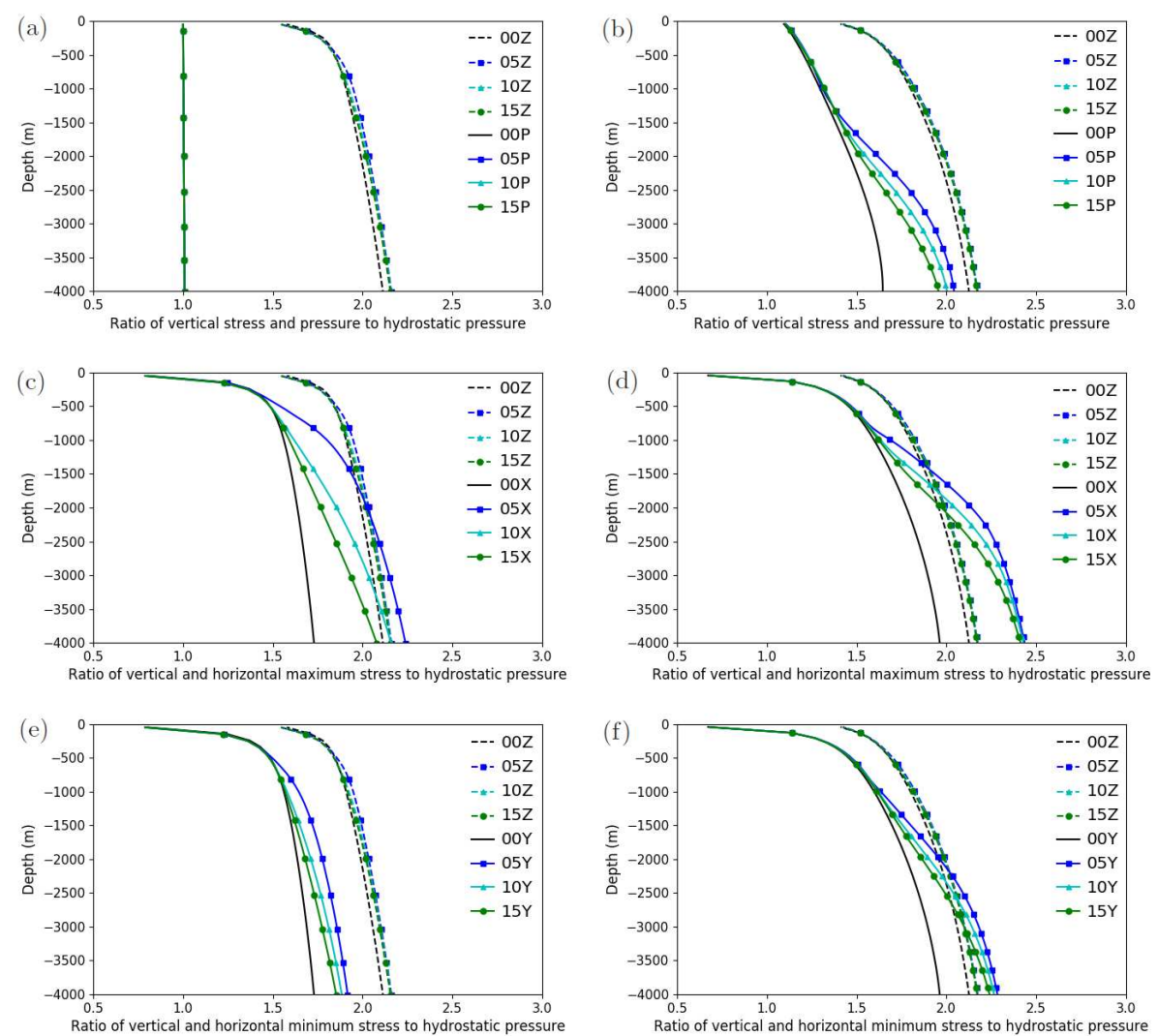

Fig. 12 For different tectonic phase duration, ratio of vertical stress and pore pressure to hydrostatic pore pressure versus depth considering a sand (a) and a shale (b), ratio of vertical stress and maximum horizontal stress to hydrostatic pore pressure versus depth considering a sand (c) and a shale (d) and ratio of vertical stress and minimum horizontal stress to hydrostatic pore pressure versus depth considering a sand (e) and a shale (f). In the legends the numbers are the duration of tectonics in million years (00 standing for the case with no tectonics), the $\mathrm{Z}$ stands for vertical stress, $\mathrm{X}$ and $\mathrm{Y}$ for the maximum and minimum horizontal stresses and the $\mathrm{P}$ for pore pressure. 

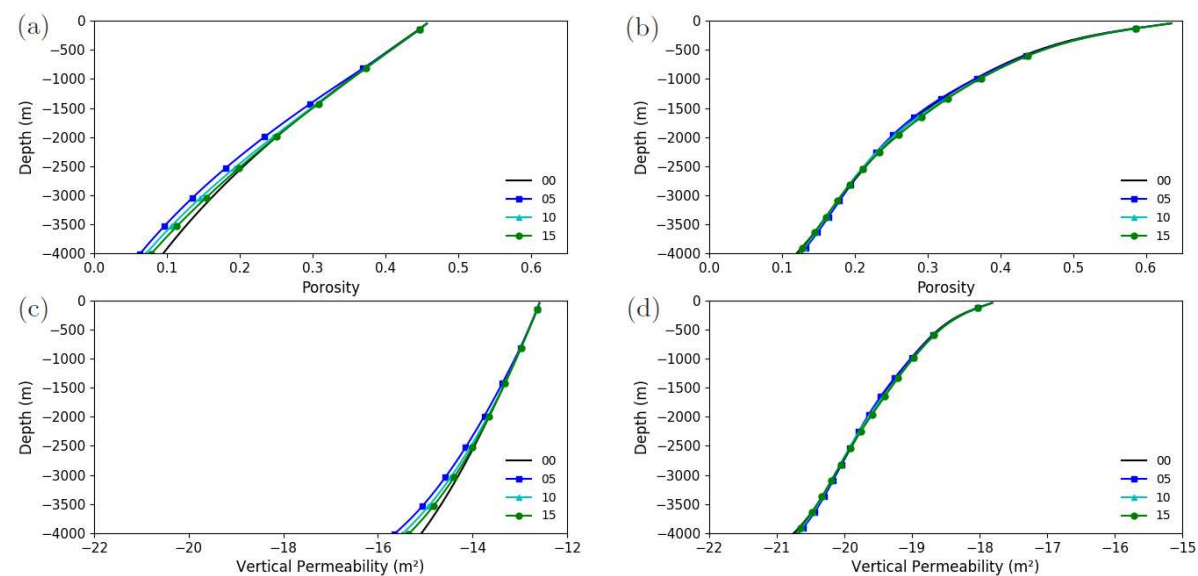

Fig. 13 Porosity versus depth for the present compaction model of Schneider for different tectonic phase duration considering a sand (a) and a shale (b) and vertical permeability versus depth in the same context for a sand (c) and a shale (d). In the legend the numbers are the duration of tectonics in million years ( 00 standing for the case with no tectonics). 

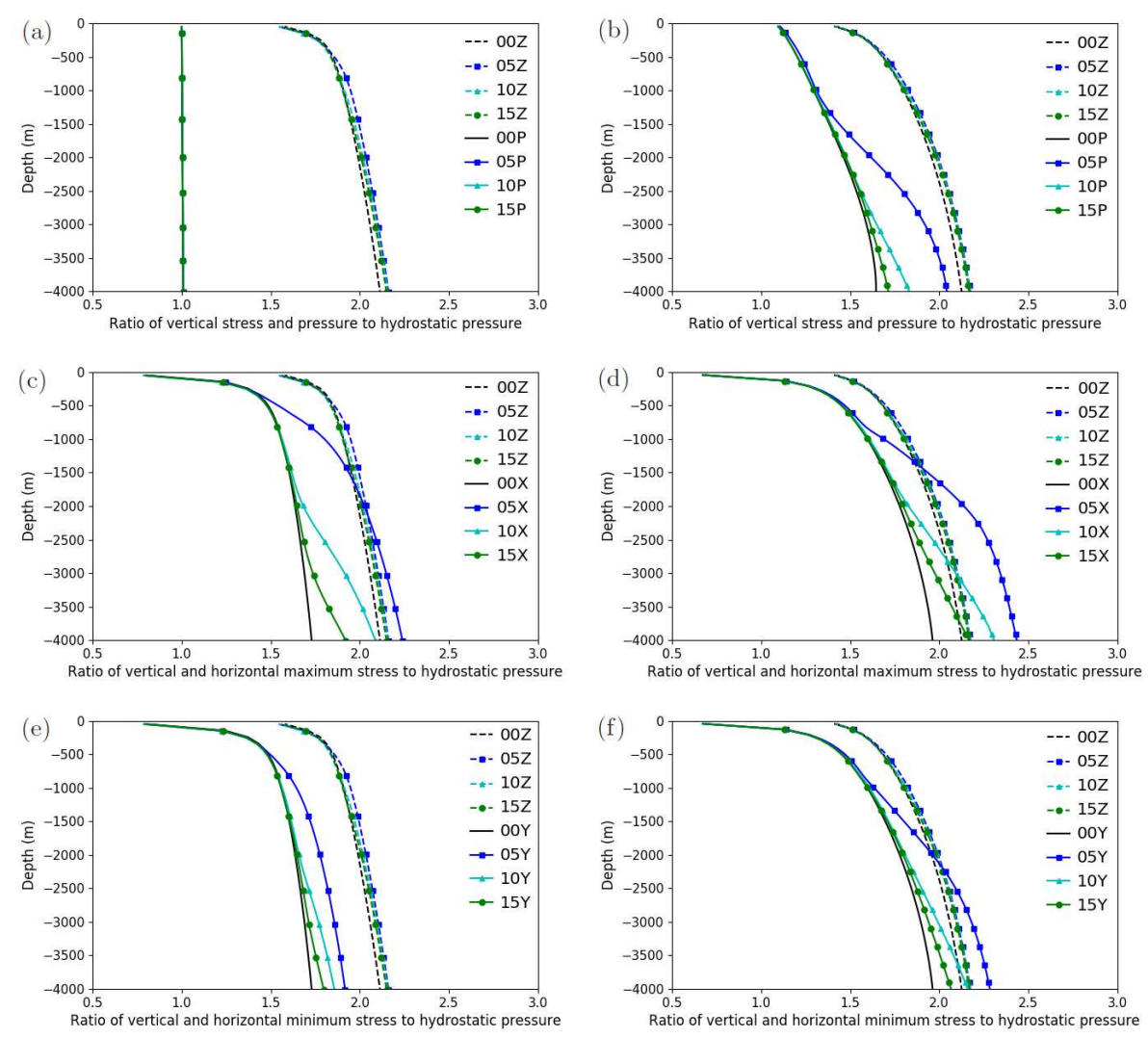

Fig. 14 For different tectonic phase age, ratio of vertical stress and pore pressure to hydrostatic pore pressure versus depth considering a sand (a) and a shale (b), ratio of vertical stress and maximum horizontal stress to hydrostatic pore pressure versus depth considering a sand (c) and a shale (d) and ratio of vertical stress and minimum horizontal stress to hydrostatic pore pressure versus depth considering a sand (e) and a shale (f). In the legends the numbers are the duration of tectonics in million years $(00$ standing for the case with no tectonics), the $\mathrm{Z}$ stands for vertical stress, $\mathrm{X}$ and $\mathrm{Y}$ for the maximum and minimum horizontal stresses and the $\mathrm{P}$ for pore pressure. 

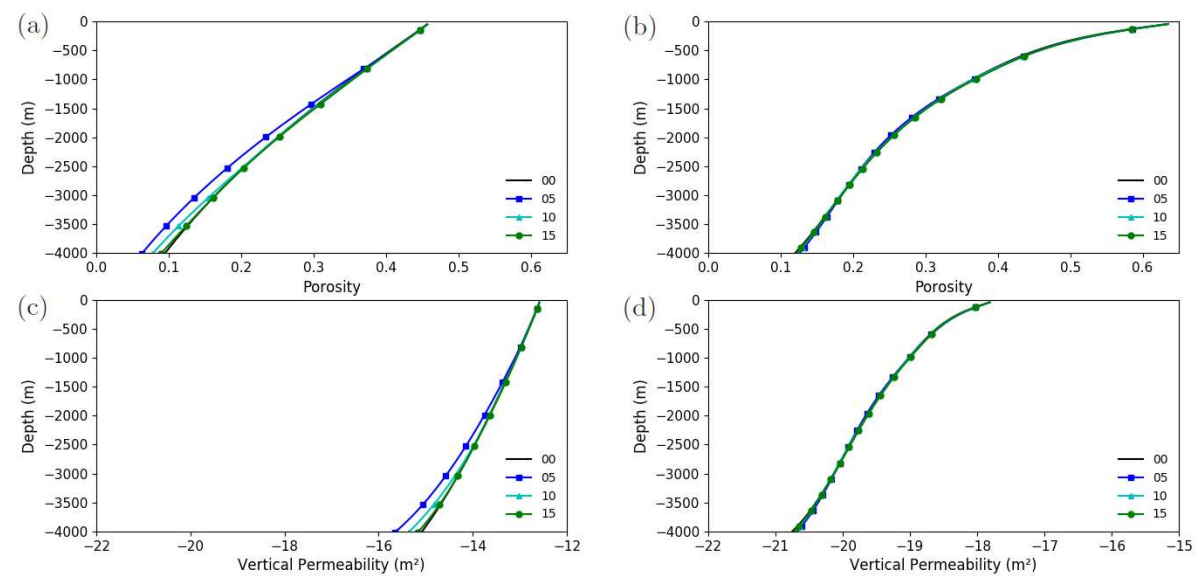

Fig. 15 Porosity versus depth for the present compaction model of Schneider for different tectonic phase age considering a sand (a) and a shale (b) and vertical permeability versus depth in the same context for a sand (c) and a shale (d). In the legend the numbers are the age of the begining of tectonics in million years ( 00 standing for the case with no tectonics).
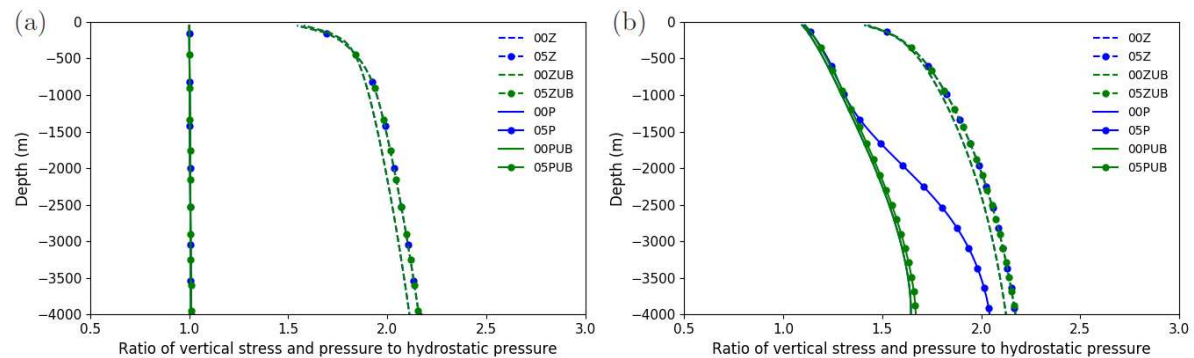

Fig. 16 With and without tectonic loading, with the present coupled framework or with uncoupled basin modelling, ratio of vertical stress and pore pressure to hydrostatic pore pressure versus depth considering a sand (a) and a shale (b). In the legends the numbers are the duration of tectonics in million years ( 00 standing for the case with no tectonics), the Z stands for vertical stress, P for pore pressure and UB stands for uncoupled basin modelling. 